\title{
Presentación del número
}

\author{
Manuel Rodríguez Zapata \\ Director de la revista RIECS; Decano de la Facultad de Medicina y Ciencias de la Salud, Universidad de \\ Alcalá; manuel.rodriguezz@uah.es
}

El 1 de diciembre se celebra el "Día Mundial contra el SIDA". Con este motivo el cuerpo central de este número de la revista RIECS está dedicado a la Infección por VIH. Hemos elegido el formato clásico de Mesa Redonda Virtual.

En nuestro medio, gracias al tratamiento antiretroviral eficaz, los pacientes con infección por VIH tienen una esperanza de vida y una calidad de vida similar a la de población general. Así, en la mesa redonda, los autores abordan los aspectos más relevantes de esta enfermedad que pueden afectar en un futuro próximo a nuestros pacientes y que deben captar la atención de los médicos que los atienden.

El profesor Santiago Moreno expone las características de la infección por VIH en el primer mundo y las acciones de futuro en esta enfermedad, haciendo énfasis en las nuevas estrategias de prevención (diagnóstico poblacional y profilaxis preexposición) y en el tratamiento del estigma social.

Otro problema al que se enfrentan las personas que viven con infección por VIH es el del envejecimiento y la fragilidad que conlleva. El profesor Miguel Torralba y la doctora Irene Bartolomé abordan, en su artículo, los aspectos clásicos de la fragilidad en la población general y la necesidad de tener herramientas adecuadas que nos permitan reconocer esta situación en los pacientes con infección por VIH. En este sentido, el profesor de CCAFYDE, Carlos Núñez Fernández nos describe los beneficios que aporta la actividad físico-deportiva en las personas con infección por VIH, tanto en el ámbito fisiológico como psicológico y las mejoras que suponen en su calidad de vida.

Por último, el doctor Rial Crestelo revisa uno de los aspectos más relevantes que condiciona la mortalidad y morbilidad de estos pacientes, como es la coinfección VIH/VHC, los avances en el tratamiento con terapias libres de interferón y el impacto que tienen en la curación de la infección por VHC.

En este número abordamos otra enfermedad con una importancia creciente en nuestro medio, debido al volumen de la población procedente de zonas de riesgo, cual es la Enfermedad de Chagas. La doctora María Teresa Sánchez de Mora revisa este problema desde el punto de vista de la Atención Primaria y la doctora Alicia Rosende Tuya expone la importancia de la transmisión vertical y la necesidad de la creación de un protocolo nacional que tenga como fin el cribado de esta enfermedad en el embarazo y la prevención de la transmisión al neonato.

La doctora Lucía Vigara Rey nos enfrenta a un problema frecuente y trascendente en la población joven y con una tendencia al alza, como es el "daño autoinducido y la ideación suicida en adolescentes" y nos describe el perfil de estos pacientes y los factores de riesgo que conducen a esta situación.

En el Aula Magna contamos con la inestimable colaboración del Profesor Jesús Oteo-Iglesias que profundiza en un problema sanitario de primer orden a nivel mundial como es el de la resistencia bacteriana y el desarrollo de la multiresistencia. A través de la lectura de su manuscrito "Comprendiendo la resistencia a antibióticos", tomamos conciencia de la complejidad de este fenómeno, de su enorme trascendencia a nivel global, y de la necesidad urgente de luchar eficazmente contra la multirresistencia mediante la implicación de todos los actores en este proceso.

El presente número se completa con un artículo original sobre "La demanda quirúrgica en el este de África. Modelos de cooperación en cirugía. Organización de una campaña sostenible" realizado por Silvestra Barrena Blázquez, graduada de Enfermería y Máster Universitario en Acción Humanitaria y el profesor José María Muguerza Huget. Raquel Aparicio del Olmo, Técnica de Cooperación al Desarrollo de la UAH, nos presenta en el espacio "Otros mundos" la "Educación y salud en Guinea Ecuatorial una relación entre la UNGE y la UAH". 
Finalmente, en el espacio Ágora, cuatro relatos cortos nos permitirán tener una visión personal y distinta del mundo, de la universidad y de la medicina.

Espero que les guste.

(c) (1)

(C) 2019 por los autores; Esta obra está sujeta a la licencia de Reconocimiento 4.0 Internacional de Creative Commons. Para ver una copia de esta licencia, visite http://creativecommons.org/licenses/by-nc-nd/4.0/. 